Genetic Control of Insect Pests. By G. Davidson. Pp. ix +158 . (Academic Press: London and New York, August 1974.) £4.00; $\$ 10.25$.

THis book provides a useful overall statement of current and proposed methods for the autogenous control of agricultural and public health pests. It is well illustrated with 16 figures, 9 of which are photographs; and there are 359 references for further reading.

The opening chapters are concerned with the sterile male technique, still the only genetic control method with a claim to success (albeit temporary). The techniques for rearing, for example, 150 million flies a week make interesting reading. Radiation, chemosterilants and hybridisation as methods for producing sterile insects are covered in detail but there is no comparison of their relative merits. The more sophisticated genetic approaches proposed for controlling insects, such as chromosome manipulation, are thoroughly covered, and although much laboratory research is being devoted to them, field trials have not been too promising.

There is scant encouragement here for those who incline to the view that genetic methods will solve our pest problems and that the end of insecticides is nigh.

Although there is little discussion of future expectations for these approaches to pest and vector control, the book offers a succinct coverage of the subject to date with, perhaps, a bias towards medically important insects, in particular, mosquitoes; no doubt a reflection of the author's experience and interests. I. Maudlin

Biological Control by Natural Enemies. By Paul DeBach Pp. 323. (Cambridge University Press: London, 1974.) $£ 5.50 ; \$ 14.95$.

THIS is a timely and valuable book, written in characteristic style by one of the world's leading biological control workers. It highlights the disasters that have followed the heavy use of broad-spectrum pesticides and emphasises the highly advantageous costbenefit ratio resulting from successful biological control projects. Numerous historical acounts of successful or partially successful campaigns are given, which highlight the colossal difficulties the early workers laboured under in the absence of global air transport, and the importance of intelligent sleuthing and intuition, as well as sound scientific understanding, in searching out the native ranges of natural enemies.

DeBach rightly emphasises the crucial importance of correct taxonomy and of seeking geographical races that are adapted to all the significant climatic and ecological situations occupied by the pest. He points out that foreign exploration for natural enemies has not yet been attempted for more than $5 \%$ of the world's pests and it is certain that an even lower percentage of weeds has been considered for attack by this means. The potential of classical biological control therefore continues to be enormous.

DeBach makes a point that will bear emphasis: "How to put everything together to choose a potentially effective enemy beforehand with certainty is still beyond our grasp"; and further ". . . the natural enemy . . . considered to be best often turned out to be inconsequential and, in fact, the best one even may be overlooked for years, as was Cyrtorhinus, the eigg predator of the sugar-cane leafhopper." Although attempts to assess in advance the potential of biological control agents must

\section{More campaigns in the pest war}

continue (and they are gradually providing a basis for sounder choices), there is still no promise of a method for accurately forecasting the impact of a particular species. One could therefore join issue with Professor DeBach when he quotes liberally from Alvah Peterson in support of a plea for the study of the $99 \%$ of insects that are unimportant to mankind. There is not a shadow of doubt that biological control would languish indefinitely if significant proportions of its rather limited manpower and resources were diverted for this purpose. In this context it is fortunate that there is little evidence that the presence of relatively ineffective introduced enemies hampers the activities of effective agents.

In addition to the great economic potential remaining in 'classical' biological control there are also prospects for the artificial augmentation of populations of natural enemies in relation to certain problems, as when parasites and predators are bred commercially in large numbers for pest control in orchards, poultry houses, dairies and feedlots.

The author also deals briefly with other non-chemical forms of pest control, such as the use of resistant plants, cultural and genetic methods, and pheromones, and he gives some useful discussion on integrated control and on the intelligent and selective use of pesticides where that is unavoidable.

This book is obviously not intended as a comprehensive treatise on biological control-indeed the vast majority of references are to American publications-but it gives a generally useful philosophy on applied entomology which all interested research workers should study.

D. F. Waterhouse

The Biochemical Mode of Action of Pesticides. By J. R. Corbett. Pp. $\mathrm{ix}+330$. (Academic: London and New York, 1974.) £7.20; \$18.50.

ANY author attempting to describe what is known about the mode of action of poisons faces an unenviable yet stimulating task, for information on the molecular basis of normal physiological activities is frequently incomplete. Impulses pass along nerves by the opening of ionic 'gates' but little is known of the mechanism operating those gates. The same applies to the coupling of electron transport with phosphorylation in mitochondria and chloroplasts, to the biochemical basis of auxin action, and to the mechanism of oxygen release in the second light reaction of photosynthesis.

As a majority of pesticides probably affect such processes, any account of their action must, of necessity, be incomplete. Dr Corbett is to be congratulated on one of the best attempts so far made to collate available evidence and to present it in a way comprehensible to all biologists possessing a background knowledge of biochemistry and supporting chemistry. It is a valuable reference book for the undergraduate library collection but is not likely to be recommended for private purchase by students of agriculture or horticulture.

The book comprises three main sections covering compounds acting respectively, on photosynthesis, nerve action and growth. They include tables of pesticides, which are valuable sources of information. The tables would have been even more useful, however, if some indication could have been given of the relative practical importance of the hundreds of compounds they contain.

An author tends to provide space according to the information available on a group of compounds, rather than in proportion to economical importance. Dr Corbett cannot, therefore, be criticised seriously for the fact that some 30 pages are devoted to the useful but locally important urea and triazine weedkillers whereas the crucially important phenoxyalkanoic acids are dismissed in five text pages. Similarly, although it is grand to encounter an author with the courage to face the unpopular truth that DDT (despite its manifold faults) has probably saved more lives than any other chemical made by man, it is a pity that it is dismissed in about eight pages.

K. A. Hassall 